\title{
A Study on the Differences in Perception among Experts and Public Officials for the Executive Agent of Environmental Affairs and National Policy Tasks
}

\author{
Junghoon $\mathrm{Ki}^{1 *}$, Soonae Park ${ }^{2}$, Youngsung Lee ${ }^{3}$, and Youngmi Lee ${ }^{2}$ \\ ${ }^{1}$ Department of Public Administration, Myongji University, Seoul 03674, Korea \\ ${ }^{2}$ Graduate School of Public Administration, Public Performance Research Center, Seoul National University, Seoul 08826, Korea \\ ${ }^{3}$ Graduate School of Environmental Studies, Seoul National University, Seoul 08826, Korea
}

\begin{abstract}
This study presents the standards for desirable local transfer of public affairs by analyzing the perceptions of experts in the academia and research institutes, as well as public officials in the environmental sector in charge of environmental affairs. The results of this study tend to be partially consistent with the results of previous studies that there is a difference in perception among respondents depending on the affiliation of experts and public officials. Among the policy tasks, there was a statistically significant difference among the respondents in perception of responsible agent for carrying out sustainable land planning and management. Regarding general environmental affairs, there was a statistically significant difference among pubic officials in different affiliations in perception of responsible executive agent for natural environment, living environment, and resource circulation.
\end{abstract}

Keywords: differences in perception by group, environmental affairs, executive body, experts

\section{Introduction}

There are various discussions about whether the executive agent of environmental affairs is the central or local government. In particular, since implementing the local government system in 1995, Korea has fully begun to transfer affairs starting with the central government's administrative regulation affairs. The environmental sector has also been constantly transferring actual authorities to local governments to reinforce the local environmental administration. However, due to the distinctiveness of environmental affairs, there is a growing controversy about the effects of local transfer. Issues have been raised about ambiguity in allocating authorities between the central and local governments, as well as about lack of preparations or competencies of the local governments to execute such affairs (Choi and Koh, 2009). Furthermore, it has also been pointed out that the fixed location of environmental resources such as regional and geographical distinctiveness or extensiveness of environmental problems have not been sufficiently considered.

\footnotetext{
This study is partially revised and improved from "Study on Promotion of Environmental Policy Implementation performance" funded by the government (Ministry of Education) in 2017. In addition, This work was supported by 2014 Research Fund of Myongii University.

Received: March 21, 2019, Revised: April 10, 2019, Accepted: April 15, 2019

First author: Junghoon Ki, E-mail: johnki@mju.ac.kr, (1) https://orcid.org/0000-0001-7554-9573

*Corresponding author: Junghoon Ki, E-mail: johnki@mju.ac.kr, (1) https://orcid.org/0000-0001-7554-9573
} 
Academic discussions about the local transfer of environmental affairs are divided into positive view and cautions view. The former reinforces resident participation, emphasizes the accountability of local governments, and seeks to actualize effective local environmental administration (Jeong, 1999; Hong, 2001, 2013; Jeong and Byun, 2011). The latter supports active intervention of the central government with emphasis on extensiveness of environmental problems or conflicts of interests (Kim and Moon, 2013). In fact, since discussions related to the local transfer of environmental affairs reflect various political, economic and social conditions, there are limitations in dealing with the issue in black and white. Thus, this study will provide the standards for desirable local transfer by analyzing the differences in perception among experts in the academia and research institutes and public officials in the environmental sector regarding policy tasks in the field of environment and the executive agent of environmental affairs. This study will examine the general direction of perception by experts and public officials through literature review, and determine whether the survey conducted in this study is consistent with the trend.

\section{Research Methods}

Recently, as most affairs are locally transferred, there have been discussions about resetting the scope in principle of whether the authorities are allocated appropriately between the central and local governments, before evaluating the effects of transfer or the administrative competencies of local governments (Ahn et al., 2015; Choi, 2015; Hwang, 2015; K.H. Ko, 2016; Ha, 2017). Choi (2015) pointed out that while efforts are constantly made to improve the administrative affairs of the central government and local governments in the Korean society today, it is not appropriate to deal with the issue of transferring affairs in terms of selecting which agent shall manage and handle certain affairs merely in the administrative and policy aspect when setting the affairs for the local governments. They emphasized that it is necessary to establish the standards to distinguish administrative affairs between the central government and local governments, and to newly organize a suitable system accordingly. Hwang (2015) also claimed that as supervision or regulation affairs in Korea are transferred to local governments, the central government is now in charge of only a very small part, which raises many questions about whether this role sharing is appropriate.

As such, various methods are recently attempted to measure and determine the effectiveness and efficiency of the local transfer of complicated and difficult administrative affairs (Ha and Choi, 2002; Choi and Koh, 2009). Previous studies that evaluated the local transfer of affairs had been focused mostly on case studies, in-depth interviews and surveys. Ko, K.Y. (2016) categorized by characteristic 1,982 cases of affairs that were completely transferred from the central government to local governments, and conducted surveys and interviews to measure the specific effectiveness. In particular, he classified the problems of transferring affairs into five types such as (1) absence of standards for allocation of authorities, (2) lack of budget and human resources, (3) inadequate laws, (4) too much workload of public officials in charge and their lack of expertise, and (5) low priority of tasks, and came up with evaluation indexes according to types of affairs. Recently, studies have also been conducted on the effectiveness of transferring affairs by the Ministry of Environment with focus on the environmental sector. Park et al. (2015) classified environmental affairs into effective environmental affairs of local governments and affairs that are difficult to manage and supervise based on the results of opinion polls conducted on experts and public officials in charge of environmental affairs in local governments in seven fields of environment (atmospheric environment, water environment, soil environment, nature conservation, resource circulation (or recycling), living environment and environmental health, and environmental policy general), and categorized them into affairs under metropolitan influence and affairs under local influence based on literature review (Table 1). 
Based on the research findings by Park et al. (2015), it would be more effective for the central government to manage the affairs in the fields such as 'atmospheric environment, water environment, nature conservation, and general environmental policy' that have the characteristics of metropolitan influence, and for the local governments to manage the affairs in the field such as 'soil environment, resource circulation, living environment and environmental health' that have the characteristics of local influence (Table 2). Local delegation and transfer of affairs with the characteristics of local influence will have greater effect (K.H. Ko, 2016; K.Y. Ko, 2016).

Choi (2015) argued that the efficiently and effectiveness are not high for currently transferred affairs, and emphasized the need to implement a prior review system of allocation of affairs to solve problems based on normative and theoretical standards. Ha (2017) also claimed that issues related to local transfer of administrative authority are caused by the complexity of law revision and irrationality in allocation of human resources and budget, and argued that it is necessary to adopt a prior review system of allocation of affairs for more rational allocation of affairs.

These studies have significance in terms of policy as they have examined the progress or performance of transfer of affairs in a comprehensive and macroscopic view and are claiming that it is necessary to change the allocation of authorities according to the principle of allocation and characteristics of affairs (Lee, 2000; Lee et al., 2003). Moreover, they all emphasize the need for new form of allocation in order to solve the problems of the current transfer of affairs

Table 1. Classification of environmental affairs by spatial impacts

\begin{tabular}{|c|c|c|c|c|c|}
\hline \multirow[b]{2}{*}{ Category } & \multicolumn{2}{|c|}{ Classification criteria } & \multicolumn{2}{|c|}{ Government unit } & \multirow[b]{2}{*}{ Manageability } \\
\hline & $\begin{array}{l}\text { Externality, broadness, } \\
\text { comprehensiveness }\end{array}$ & $\begin{array}{l}\text { Locality, } \\
\text { responsiveness }\end{array}$ & $\begin{array}{c}\text { Metropolitan } \\
\text { authority }\end{array}$ & $\begin{array}{c}\text { Local } \\
\text { authority }\end{array}$ & \\
\hline $\begin{array}{l}\text { Metropolitan } \\
\text { influence }\end{array}$ & $\begin{array}{l}\cdot \text { Atmospheric environment } \\
\cdot \text { Water environment } \\
\cdot \text { Nature conservation } \\
\cdot \text { Environmental Policy } \\
\text { General }\end{array}$ & & $\begin{array}{l}\cdot \text { Atmospheric environ- } \\
\text { mental Affairs } \\
\cdot \text { Water quality and water } \\
\text { management environ- } \\
\text { mental affairs }\end{array}$ & $\begin{array}{l}\text { Atmospheric } \\
\text { environmental affairs } \\
\text { - Water quality and } \\
\text { water management } \\
\text { environmental affairs }\end{array}$ & $\times$ \\
\hline $\begin{array}{l}\text { Local } \\
\text { influence }\end{array}$ & & $\begin{array}{l}\cdot \text { Soil Environment } \\
\cdot \text { Resource circulation } \\
\cdot \text { Living Environment And } \\
\text { Environmental Health }\end{array}$ & $\begin{array}{l}\text { Water and sewage } \\
\text { management Affairs }\end{array}$ & $\begin{array}{l}\text { Resource circulation and } \\
\text { resource recycling } \\
\text { environmental Affairs }\end{array}$ & ○ \\
\hline
\end{tabular}

Note. Reprinted from "A study on the problems and improvement plan of local offices of the Korea Ministry of Environment," by Park, S.C. et al., 2015, p. 160. Sejong, Korea: Ministry of Environment.

Table 2. Effective allocation of authority for transfer of affairs by the Ministry of Environment

\begin{tabular}{lccl}
\hline Category & $\begin{array}{c}\text { Central } \\
\text { government }\end{array}$ & $\begin{array}{c}\text { Local } \\
\text { government }\end{array}$ & Remarks \\
\hline Atmospheric environment & $\circ$ & $\circ$ & $\cdot$ Distribution according to the characteristics of individual affairs \\
Natural environment & $\circ$ & $\circ$ & $\cdot$ Distribution according to the characteristics of individual affairs \\
Soil environment & - & $\circ$ & \\
Nature conservation & $\circ$ & - & · Distribution according to the characteristics of individual affairs \\
Resource circulation & $\circ$ & $\circ$ & \\
Environmental health & - & $\circ$ & \\
General environmental policy & - & $\circ$ & \\
\hline
\end{tabular}

Note. Reprinted from "A study on the problems and improvement plan of local offices of the Korea Ministry of Environment," by Park, S.C. et al., 2015, p. 163. Sejong, Korea: Ministry of Environment. 
(Lee et al., 2008; Park, 2013; Park et al., 2014; Moon, 2013). Nonetheless, there has been almost no in-depth analysis on the different perceptions among experts or public officials that are actual subjects of research or no policies provided based on such analysis. Thus, there may be significance in determining the desirable executive agent of affairs and scope for transfer of affairs through such research.

The interesting fact shown in previous studies with regard to this research method is that the respondents had different views about the executive agent of environmental affairs depending on their affiliation (Jeong et al., 2013; Park et al., 2013; Park et al., 2015). Professors or researchers were relatively more neutral or objective than other groups, whereas public officials were relatively sensitive about the role of their affiliation or interests. Public officials in the Ministry of Environment tended to emphasize the role of the central government in environmental affairs, whereas public officials in local governments gave different views depending on whether they belong to metropolitan or basic local governments. Many public officials in the metropolitan governments responded that the metropolitan governments must be in charge of major environmental affairs except international agreements, whereas public officials in the basic local governments were somewhat negative about transferring environmental affairs to local governments due to lack of expertise and limitations in finances and human resources (Jeong et al., 2013; Park et al., 2013; Park et al., 2015).

This study conducted an in-depth focus group interview (FGI) in November 2017 on 20 experts in related fields such as environmental policy, local autonomy and governance, and collected and analyzed opinions about the current status and diagnosis of performance as well as improvement plans for environmental policy implementation. Furthermore, this study conducted by Computer Assisted Web Interview (CAWI) for a month from October to November 2017 on total 304 public officials in charge of environmental affairs working in the Ministry of Environment, local environmental offices, and metropolitan and basic local governments.

Among the overall contents of the interview and online survey, this study conducts statistical analysis and interpretation on the differences in perception among groups with focus on the items as shown in Table 3.

\section{Results and Discussion}

The results of this study are comprised of two steps. The first step is analyzing the contents of the interview with ex-

Table 3. Contents used in this study from the interview with experts and the survey on public officials

Group

.

Experts

.

Public officials
Question

There have been constant discussions about the ambiguity in allocation of authorities between the central and local governments due to issues such as competencies of local governments in executing environmental affairs, fixed location of environmental resources, and regional and geographical distinctiveness. The following table shows the details of Moon Jae-in administration's policy tasks in the field of environment. Please provide specific opinions about the importance and urgency of each project and the allocation of roles between the central and local governments (policy planning, implementation, financial burden, monitoring/regulation, performance evaluation, etc.).

Executive agent of environmental affairs for policy tasks in the field of environment (ensuring safety in daily lives, making air cleaner and dust-free, carrying out sustainable land planning and management, carrying out the implementation of the Paris Agreement on Climate Change)

- Effect of local delegation and transfer of environmental affairs (atmospheric environment, natural environment, living environment, resource circulation)

- General characteristics of respondents 
perts, and the second step is showing the differences between the public officials groups based on the contents of the survey.

\section{Contents of the interview with experts}

There are some agreement and disagreement among experts regarding how the authorities and roles must be allocated between the central and local governments in order to successfully implement the four policy tasks (ensuring safety in daily lives, making air cleaner and dust-free, carrying out sustainable land planning and management, carrying out the implementation of the Paris Agreement on Climate Change) in the field of environment by the Moon Jae-in government. Regardless of affiliation, experts agree that the central government must take the lead in establishing and implementing policies related to making air cleaner and dust-free and carrying out sustainable land planning and management. However, there was a difference among professors and researchers, public officials in the central government, civic groups, and public officials in local governments in terms of ensuring safety in daily lives and carrying out the implementation of the Paris Agreement on Climate Change. For ensuring safety in daily lives, experts in the academia and public officials in the central government perceive that it is desirable for the central government to have powerful authority regardless of the matter such as chemical substances and food safety, whereas civic groups and public officials in local governments argue that the authority and role of local governments must be increased for food safety. With regard to carrying out the implementation of the Paris Agreement on Climate Change, experts in the academia and public officials in the central government think that it is desirable for the central government to have limited authority and role such as planning the overall policy scheme and modifying laws and systems, whereas civic groups and public officials in local governments claim that the central government shall fully lead this matter while local governments provide assistance. Detailed opinions among groups of experts are listed in Table 4.

\section{Contents of the survey taken by public officials}

\section{National Policy tasks}

(1) Executive agent for ensuring safety in daily lives

With regard to the executive agent suitable for ensuring safety in daily lives, more than half of the respondents (57.2\%) claimed that the Ministry of Environment must be in charge, followed by local environmental offices (27.0\%), metropolitan governments (22.4\%), and basic local governments (11.2\%) (Figure 1). Meanwhile, as a result of cross-tabulation analysis, there was no statistically significant difference among affiliations, indicating that public officials somewhat have an agreement.

(2) Executive agent for making air cleaner and dust-free

For making air cleaner and dust-free, more than half of the respondents (52.3\%) also claimed that it is more efficient and desirable for the Ministry of Environment to be in charge, followed by metropolitan governments (34.5\%), local environmental offices (24.0\%), and basic local governments (16.4\%) (Figure 2). In particular, a higher ratio of respondents stated that affairs related to fine dust must be carried out by upper-level local governments compared to other environmental affairs. This is an outcome of the 'Principle of Locality and Subsidiarity' among the principles of allocating local affairs, because fine dust is closely related to industrial characteristics of the region as well as geographical and topographical distinctiveness, and in many cases upper-level local governments are performing tasks related to licensing and regulation. However, the result of cross-tabulation analysis showed that the responses had no statistically significant difference among affiliations. 
Table 4. Perception on the executive agent of policy tasks in the field of environment by group of experts

Group
Contents

- Ensuring safety in daily lives: Considering the extensiveness of managing chemical substances and food safety, it is necessary to establish and manage pan-national policies. Thus, it is desirable for the central government to be in charge of policy planning (establishing a risk assessment system, etc.), financial support, R\&D (building DB on hazardous substances, etc.), and performance evaluation. Local governments shall actually implement the policies established by the central government by enacting detailed ordinances, and monitor and regulate them. However, roles and authorities must be allocated under the system of collaborative governance.

- Making air cleaner and dust-free: Like ensuring safety in daily lives, due to the extensiveness of the fine dust issue, the central government must be in charge of policy planning, R\&D and performance evaluation, whereas local governments perform the role of execution, monitoring and regulation. However, there must be collaborative governance between the central and local governments for monitoring and regulating air discharge

Professors and researchers agencies.

- Carrying out sustainable land planning and management: The central government must establish and modify legal systems such as the Framework Act on Sustainable Development and spatial environment planning, and be in charge of policy planning, R\&D, financial support, performance evaluation, and monitoring and regulation of Baekdudaegan Mountain Range and the Four Major Rivers, whereas local governments perform the role of execution, monitoring and regulation in cooperation with the central government.

- Carrying out the implementation of the Paris Agreement on Climate Change: The central government must be in charge of policy establishment (effective management and market activation of the emission trading scheme, regional allocation to reduce greenhouse gas, tightening of emission standards, etc.), international negotiations, R\&D, public relations and performance evaluation, whereas local governments establish specific implementation plans considering regional characteristics to implement, monitor and regulate the central government's policies.

- Ensuring safety in daily lives: The central government's role is important in policy planning, implementation and management in terms of managing chemical substances, but local governments may have a more important role in food safety because regional characteristics are different.

- Making air cleaner and dust-free, carrying out sustainable land planning and management: The central

Civic group activists government must express the policy will and set the direction, whereas local governments implement the policies.

- Carrying out the implementation of the Paris Agreement on Climate Change: The central government must take the lead in establishing and implementing policies, while individual policy efforts are made at the level of local governments.

- Ensuring safety in daily lives: The central government must be in charge of policy planning and implementation, financial support and performance evaluation, whereas local governments develop related competencies and are put in charge of monitoring and regulation.

Public officials in the central and local governments
- Making air cleaner and dust-free, carrying out sustainable land planning and management: The central government must be in charge of policy planning and financial support, whereas local governments are in charge of actual implementation, monitoring and regulation. It is more desirable for the central government to have a bigger role.

- Carrying out the implementation of the Paris Agreement on Climate Change: The central government must perform a leading role in establishing and implementing greenhouse gas reduction policies, while local governments establish detailed policies and assist the central government.

(3) Executive agent for carrying out sustainable land planning and management

For carrying out sustainable land planning and management, more than half of the respondents (55.6\%) also claimed that it is suitable for the Ministry of Environment to be in charge, followed by local environmental offices (35.2\%), metropolitan governments $(28.0 \%)$, and basic local governments (8.2\%) (Figure 3). As a result of cross-tabulation analysis, there was a significant difference among affiliations.

In particular, the highest ratio of public officials that belong to metropolitan governments responded that metropolitan governments are the most desirable executive agent. Among forms of governance (central governance, local governance, 


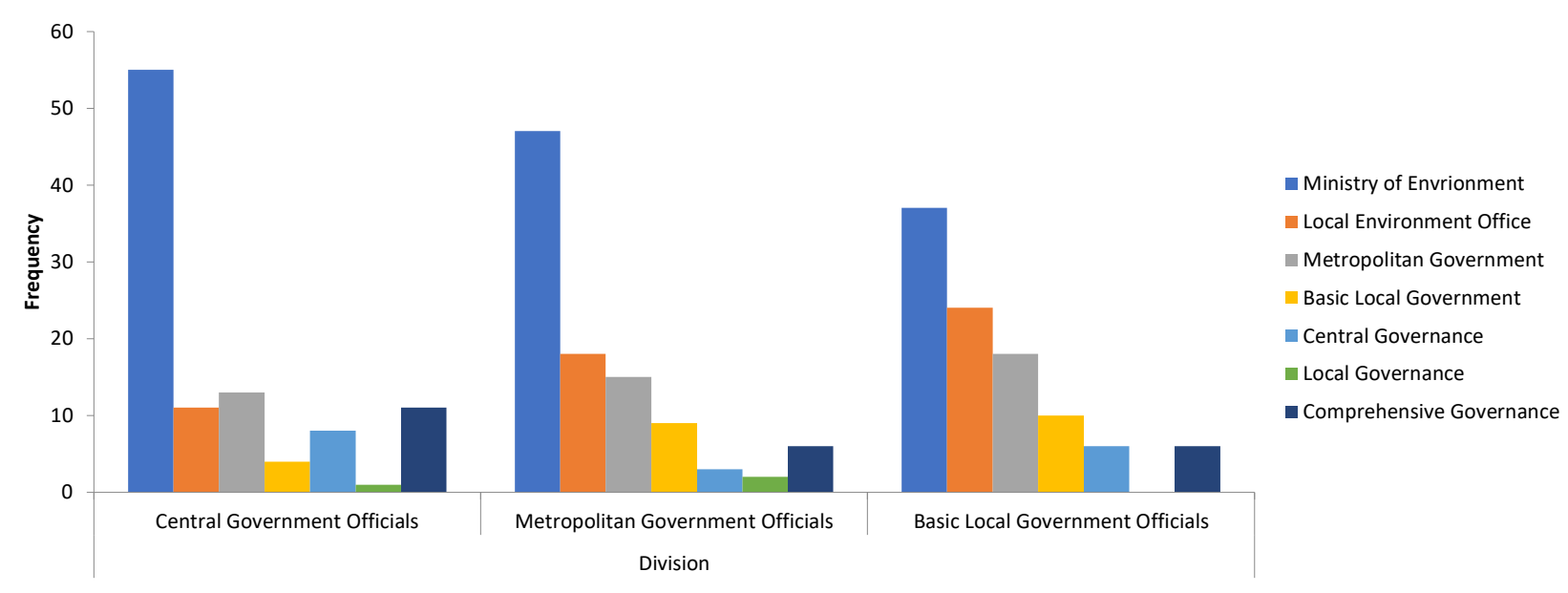

Figure 1. Environmental sector public officials' perception of executive agent responsible for ensuring safety in daily lives.

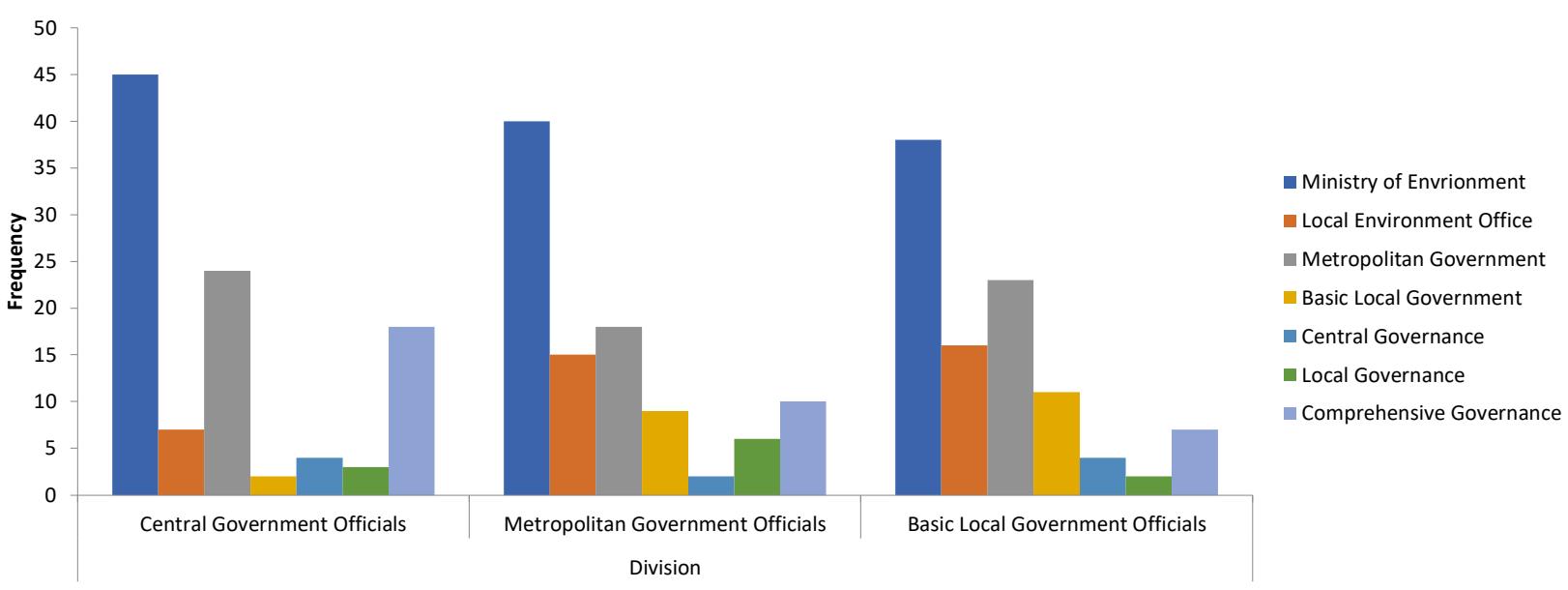

Figure 2. Environmental sector public officials' perception of executive agent responsible for fine dust regulatory actions.

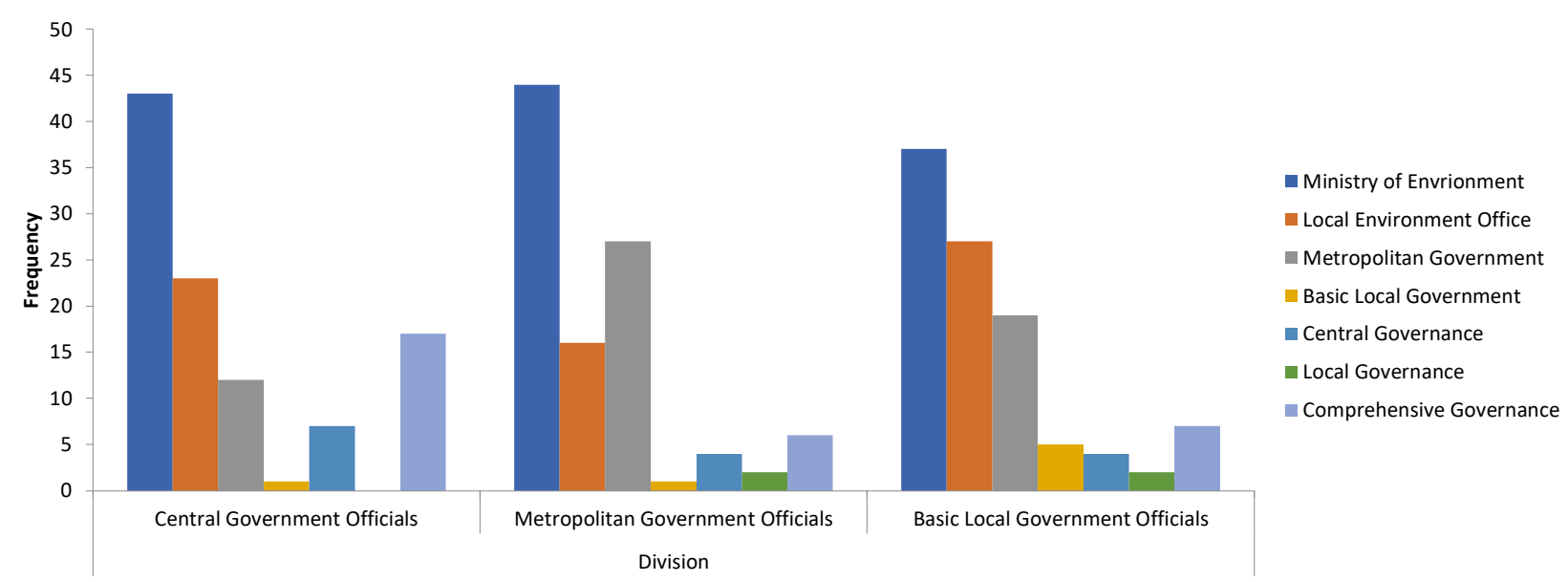

Figure 3. Environmental sector public officials' perception of executive agent responsible for carrying out sustainable land planning and management. 
comprehensive governance), most respondents claimed that comprehensive governance with a cooperative system between the central and local governments must be in charge.

(4) Executive agent for carrying out the implementation of the Paris Agreement on Climate Change

Most of the respondents (71.7\%) chose the Ministry of Environment has the leading agent for carrying out the implementation of the Paris Agreement on Climate Change, followed by local environmental offices (21.1\%), metropolitan governments (19.7\%), and basic local governments (8.9\%) (Figure 4). As a result of cross-tabulation analysis, there was no statistically significant difference among affiliations.

In sum, regarding the executive agent suitable for the four policy tasks in the field of environment, public officials think that it is desirable for the Ministry of Environment (central government) to be in charge of all four tasks, especially carrying out the implementation of the Paris Agreement on Climate Change (Table 5). This may be due to the fact that the relevant task requires advanced planning and executive power that is difficult for local environmental offices or local governments, such as building cooperative relations with other countries and forecasting climate change risks based on specialized competencies.

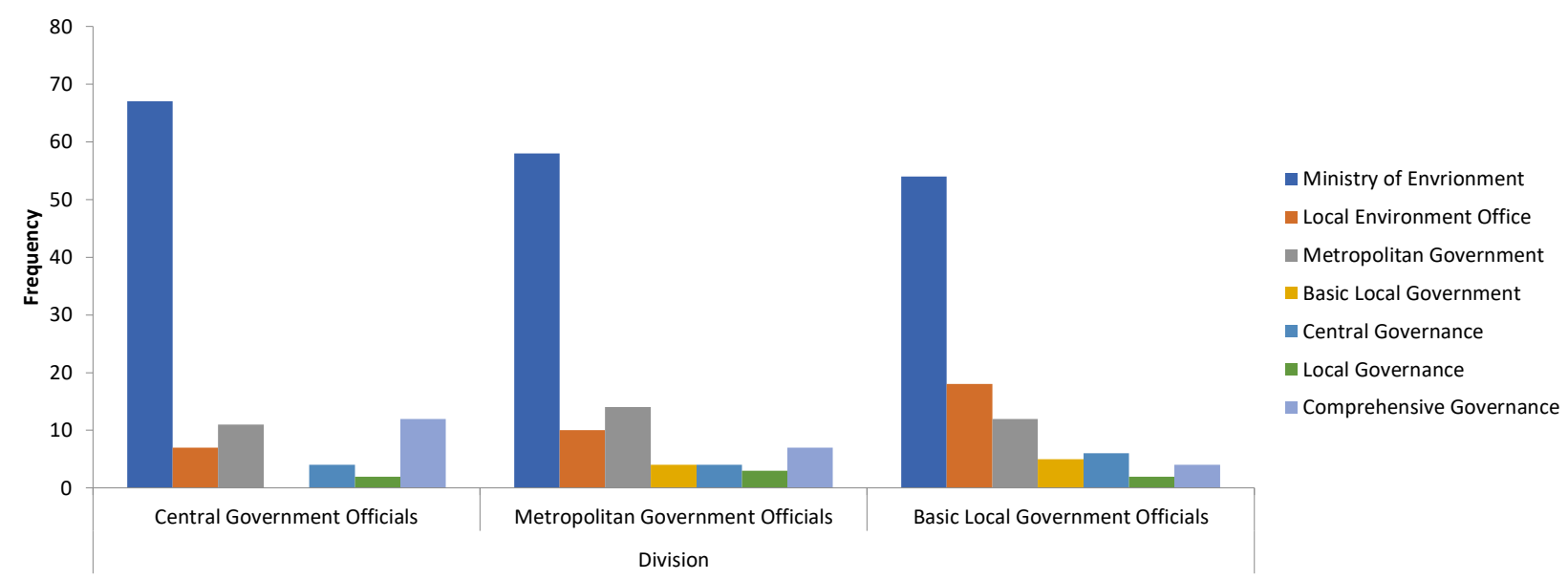

Figure 4. Environmental sector public officials' perception of executive agent responsible for carrying out the implementation of the Paris Agreement on climate change.

Table 5. Environmental sector public officials' perception of executive agent responsible for environmental affairs and policy tasks $(\mathrm{N}=304)$

\begin{tabular}{lcccc}
\hline & $\begin{array}{c}\text { Ministry of } \\
\text { Environment } \\
(\%)\end{array}$ & $\begin{array}{c}\text { Provinces, basins and } \\
\text { Atmospheric Environment Agency } \\
(\%)\end{array}$ & $\begin{array}{c}\text { Metropolitan } \\
\text { Authority } \\
(\%)\end{array}$ & $\begin{array}{c}\text { Local } \\
\text { Authority } \\
(\%)\end{array}$ \\
\hline $\begin{array}{l}\text { Strengthening } \\
\text { life safety }\end{array}$ & 57.2 & 27.0 & 22.4 & 11.2 \\
$\begin{array}{l}\text { Fine dust } \\
\text { regulation }\end{array}$ & 52.3 & 34.5 & 24.0 & 16.4 \\
$\begin{array}{l}\text { Creating a sustainable } \\
\text { land environment }\end{array}$ & 55.6 & 35.2 & 28.0 & 8.2 \\
$\begin{array}{l}\text { Paris Agreement performance } \\
\text { system establishment }\end{array}$ & 71.7 & 21.1 & 19.7 & 8.9 \\
\hline
\end{tabular}




\section{Environmental Affairs}

(1) Executive agent for atmospheric environment

Most respondents (44.4\%) claimed that it is efficient and desirable for the Ministry of Environment to be in charge of environmental affairs in atmospheric environment, followed by metropolitan governments (34.9\%), local environmental offices (28.9\%), and basic local governments (26.0\%) (Figure 5). As a result of cross-tabulation analysis, there was no significant difference among affiliations.

(2) Executive agent for natural environment

Half the respondents (49.7\%) stated that local environmental offices are the most suitable executive agent for natural environment, followed by metropolitan governments (37.5\%), basic local governments (27.3\%), and the Ministry of Environment (20.7\%) (Figure 6).

The result of cross-tabulation analysis showed that there was a statistically significant difference among affiliations for environmental affairs in natural environment. Public officials in the central government laid most stress on the role

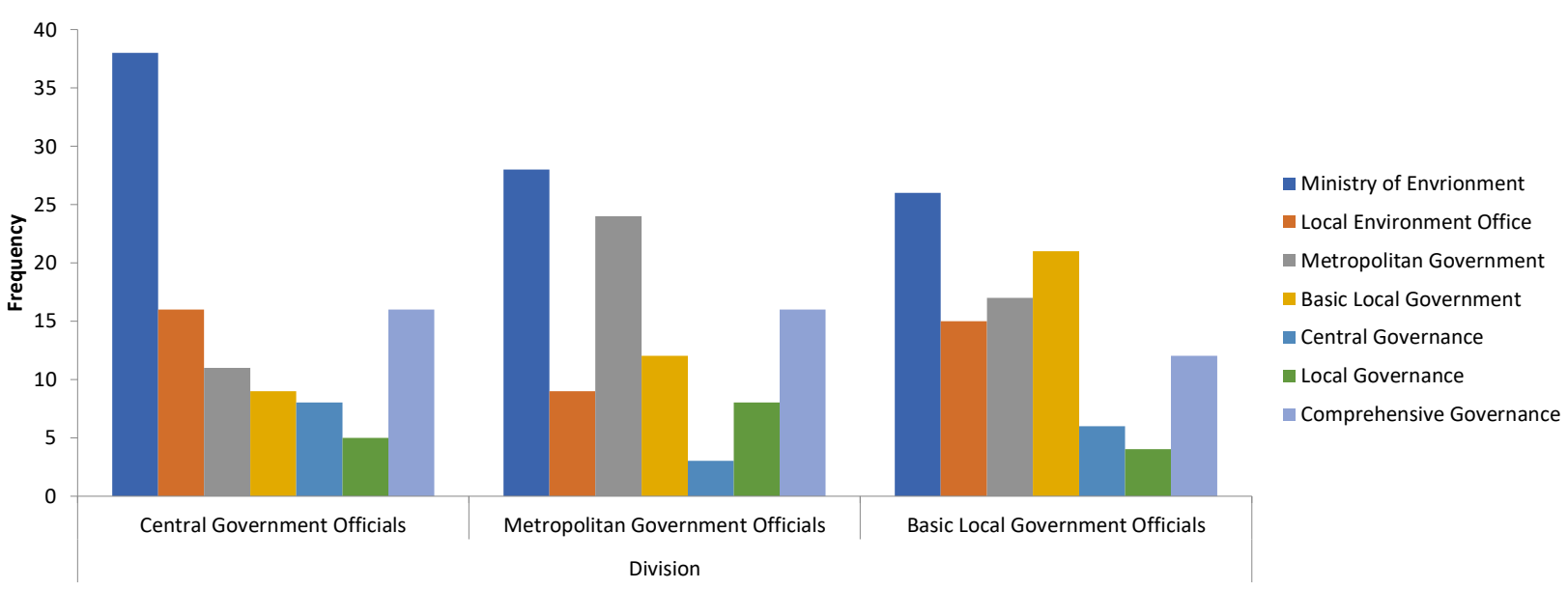

Figure 5. Environmental sector public officials' perception of executive agent responsible for atmospheric environment.

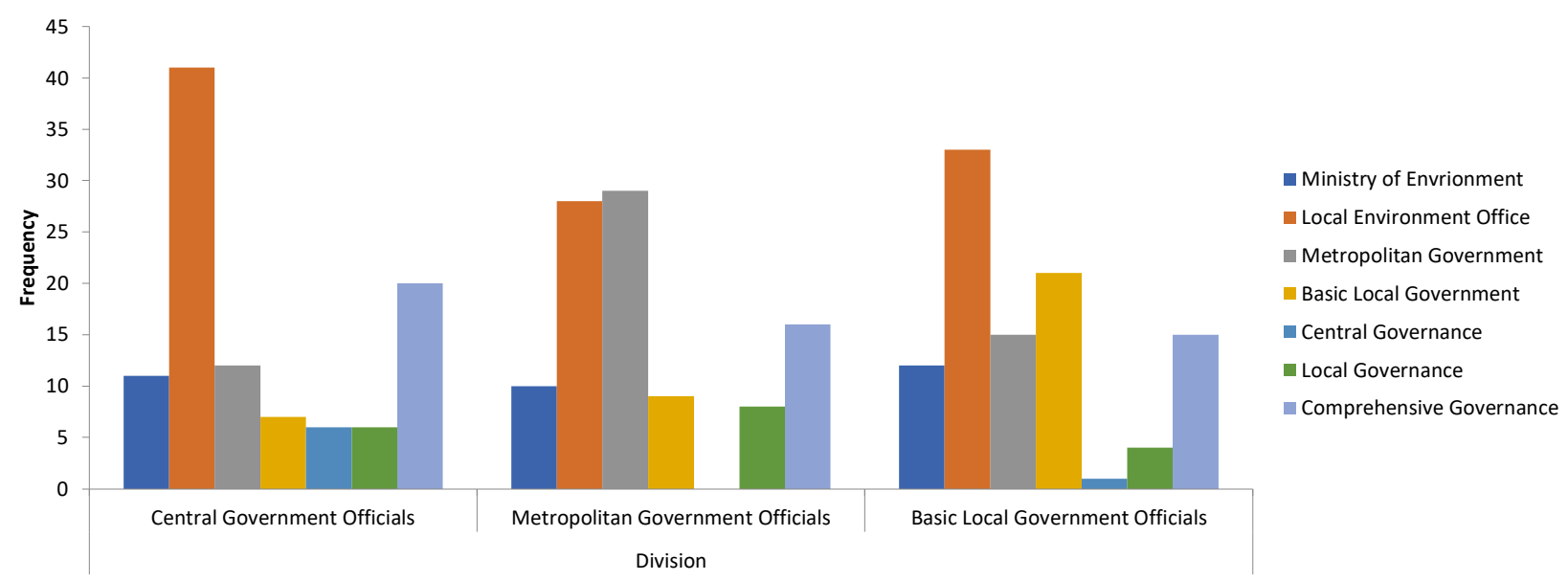

Figure 6. Environmental sector public officials' perception of executive agent responsible for natural environment. 
of environmental office, whereas public officials in metropolitan and basic local governments value the role of their own affiliation as much as environmental office. Meanwhile, among the forms of governance (central governance, local governance, comprehensive governance), the highest ratio of respondents claimed that it is suitable for comprehensive governance with a cooperative system between the central and local governments to be in charge.

(3) Executive agent for living environment

Most respondents claimed that basic local governments (57.6\%) are the most efficient executive agent for environmental affairs in the living environment, followed by metropolitan governments (38.2\%), local environmental offices (19.4\%), and the Ministry of Environment (16.4\%) (Figure 7).

The result of cross-tabulation analysis showed that there was a statistically significant difference among affiliations for environmental affairs in living environment. Public officials in the central government emphasized the role of metropolitan governments, whereas public officials in the metropolitan and basic local governments are laying more emphasis on the role of basic local governments. Among the forms of governance, the highest ratio of respondents claimed that it is suitable for local governance with a cooperative system between the metropolitan and basic local governments to be in charge.

(4) Executive agent for resource circulation

Half the respondents (48.4\%) chose basic local governments as the most suitable executive agent for environmental affairs in resource circulation, followed by metropolitan governments (38.5\%), Ministry of Environment (20.4\%), and local environmental offices (19.7\%) (Figure 8).

The result of cross-tabulation analysis showed that there was a statistically significant difference among affiliations for environmental affairs in resource circulation. Public officials in the central government emphasized the role of metropolitan governments, whereas public officials in the metropolitan and basic local governments are laying more emphasis on the role of basic local governments. Among the forms of governance (central governance, local governance, comprehensive governance), the highest ratio of respondents claimed that it is suitable for comprehensive governance with a cooperative system between the central and local governments to be in charge.

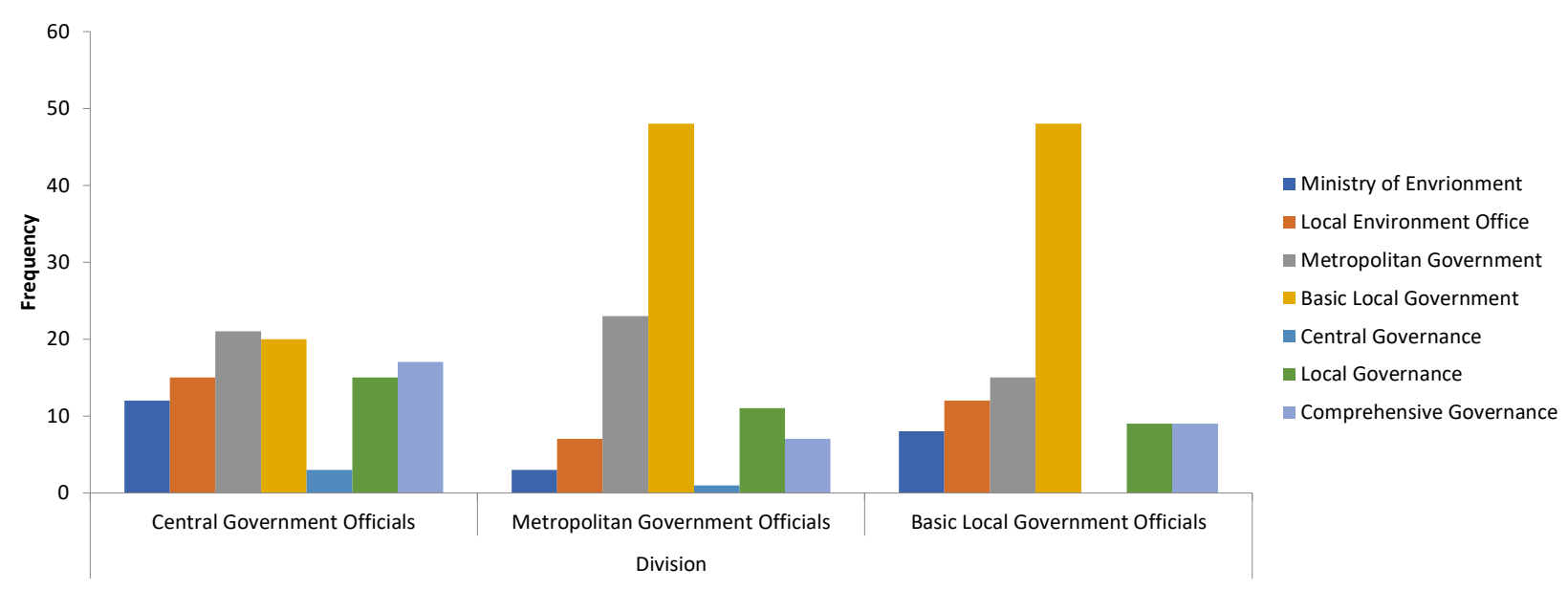

Figure 7. Environmental sector public officials' perception of executive agent responsible for living environment. 


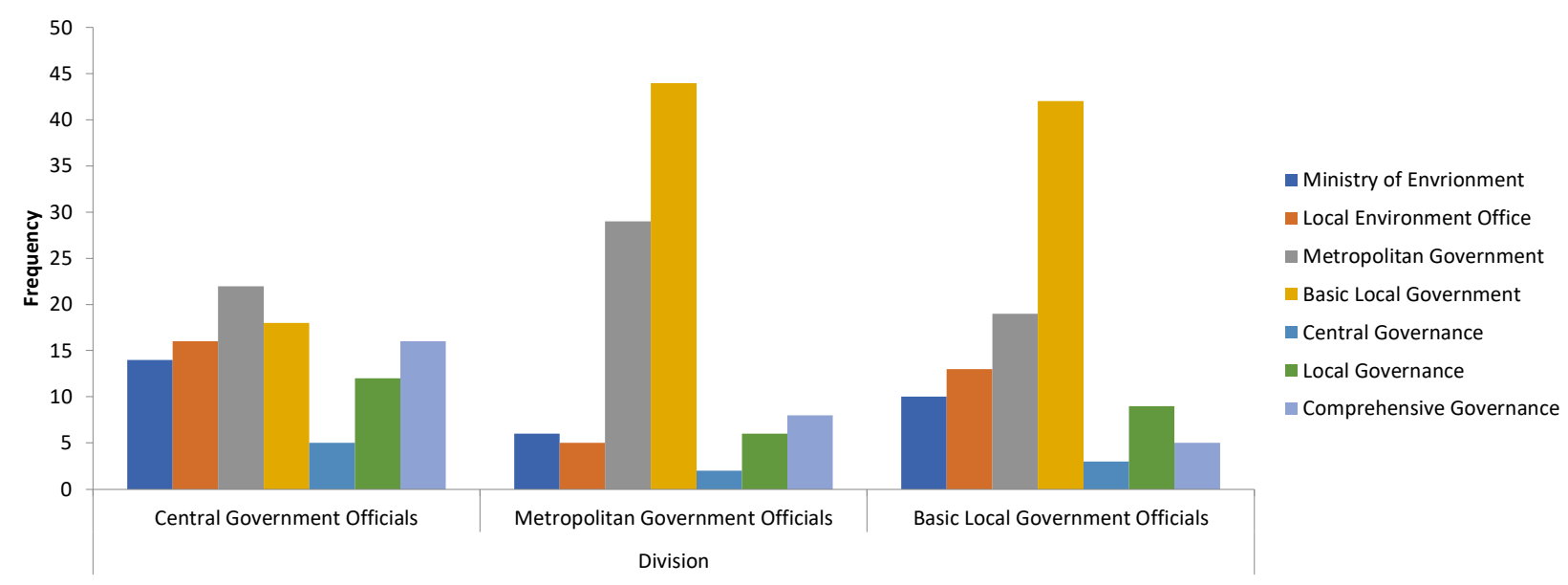

Figure 8. Environmental sector public officials' perception of executive agent responsible for resource circulation.

With regard to the executive agent for Moon Jae-in government's four policy tasks in the field of environment, public officials are showing the following perceptions depending on their affiliation (Ministry of Environment, metropolitan governments, basic local governments). More than half the respondents (57.2\%) claimed that the Ministry of Environment is the suitable executive agent for ensuring safety in daily lives. There was no statistical significance among affiliations, indicating that the public officials are somewhat in an agreement. Most of them (52.3\%) also responded that it is efficient and desirable for the Ministry of Environment to be in charge of making air cleaner and dust-free, but a higher ratio of respondents claimed that affairs related to fine dust must be executed by metropolitan governments compared to other environmental affairs. However, there was no statistically significant difference among affiliations. The highest ratio of respondents (55.6\%) also claimed that the Ministry of Environment must be in charge of carrying out sustainable land planning and management, and as a result of statistical analysis, there was a significant difference among affiliations. In particular, the highest ratio of public officials in the metropolitan governments responded that the metropolitan governments are the most desirable executive agent. Most of the respondents (71.7\%) also pointed out that the Ministry of Environment must be in charge of carrying out the implementation of the Paris Agreement on Climate Change, and there was no statistically significant difference among affiliations.

In sum, regarding the executive agent suitable for the four policy tasks in the field of environment, public officials think that it is desirable for the Ministry of Environment (central government) to be in charge of all four tasks, especially carrying out the implementation of the Paris Agreement on Climate Change.

As for executive agent in general environmental affairs that are not national policy tasks, the public officials had the following perceptions. Most of them (44.4\%) responded that it is efficient and desirable for the Ministry of Environment to be in charge of environmental affairs in atmospheric environment, and there was no statistically significant difference among affiliations. Half the respondents (49.7\%) claimed that the most suitable executive agent in natural environment is local environmental offices, and there was a statistically significant difference among affiliations. Public officials in the central government laid most emphasis on the role of environmental office, whereas public officials in the metropolitan and basic local governments valued the role of their own affiliation as much as environmental office.

Most respondents (57.6\%) chose basic local governments as the efficient executive agent for environmental affairs in 
living environment, and there was a statistically significant difference among affiliations. Public officials in the central government emphasized the role of metropolitan governments, while public officials in the metropolitan and basic local governments are laying more emphasis on the role of basic local governments. Half the respondents (48.4\%) chose basic local governments as the most suitable executive agent for environmental affairs in resource circulation, and there was a statistically significant difference among affiliations. Public officials in the central government emphasized the role of metropolitan governments, whereas public officials in the metropolitan and basic local governments are more emphasizing the role of basic local governments.

\section{Conclusion}

There are some agreement and disagreement among experts regarding how the authorities and roles must be allocated between the central and local governments in order to successfully implement the four policy tasks in the field of environment by the Moon Jae-in government. Regardless of affiliation, experts agree that the central government must take the lead in establishing and implementing policies related to making air cleaner and dust-free and carrying out sustainable land planning and management. However, there was a difference among professors and researchers, public officials in the central government, civic groups, and public officials in local governments in terms of ensuring safety in daily lives and carrying out the implementation of the Paris Agreement on Climate Change.

The results of this study are partially consistent with the results of previous studies that there is a difference in responses among experts and public officials depending on their affiliations. However, the results were somewhat different among different fields of environment. There was no difference among affiliations in living safety, making air cleaner and dustfree, and carrying out the implementation of the Paris Agreement on Climate Change for the government's policy tasks, but there was a difference between public officials in metropolitan governments and respondents in other affiliations for carrying out sustainable land planning and management. As for the executive agent of general environmental affairs that are not national policy tasks, there was no difference among affiliations in atmospheric environment, but there was a statistical difference among affiliations for natural environment, living environment, and resource circulation, which is similar to the results of previous studies.

The following policy implications can be obtained from the results of this study. First, the local transfer of environmental affairs shall not be carried out in a lump, but shall be taken care of by the agency or government that can effectively handle the affairs. The tasks shall be distributed according to the field of affairs to the Ministry of Environment, local environmental offices, and metropolitan and basic local governments. Second, there is a need for collaboration between two or more levels of the government in such environmental affairs, which is proved by the survey responses about governance. Comprehensive governance in which all levels of the government participate is important in the field of atmospheric and natural environment. Third, it is also necessary to come up with a process to rationally determine the executive agents of environmental affairs or policy tasks.

\section{References}

Ahn, H.K., C.S. Hahm, and J.H. Seo. 2015. Building collaborative governance between the central and local governments. Seoul, Korea: The Korea Institute of Public Administration.

Choi, B.S. 2015. Problems and improvement tasks of local self-government work allocation criteria. Local Govern. Law J. [Korean Local Government Law Association] 15(4):69-95.

Choi, C.I. and J.K. Koh. 2009. An analysis of the effect of decentralized environmental regulation. J. Korea Plan. Assoc. 
44(1):259-272.

Ha, H.S. and Y.C. Choi. 2002. A comparative study on the differential decentralization system: Focusing on Britain, USA, Japan and Nordic Countries. Korean Public Adm. Rev. 36(2):109-127.

Ha, H.Y. 2017. Issues and tasks related to local governance transfer of central administrative authority (Issue and Point, No. 1280). Seoul, Korea: National Assembly Research Service.

Hong, J.H. 2001. Introduction of differential transfer system in the local transfer of central government affairs. J. Local Govern. Stud. 13(3):5-24. Retrieved from http://www.kalgs.or.kr

Hong, J.H. 2013. Promotion of effective local transfer of central government affairs. Proceedings of the Korean Association for Public Administration 2013 Summer Conference.

Hwang, G.Y. 2015. Environmental inspection and control- Present state and policy direction-. Environ. Law Res. 37(2):75-101. Retrieved from http://www.ela.or.kr

Jeong, H.S. 1999. Sharing responsibility between central and local governments in environmental administration. J. Soc. Sci. [Chungbuk national university] 16:199-216.

Jeong, H.S. and B.S. Byun. 2011. Environmental policy. Seoul, Korea: Pakyoungsa.

Jeong, W.H., C.H. Lee, S.R. Kim, S.A. Park, W.C. Jang, H.S. Lee, S.Y. Hwang, H.Y. Kwon, M.K. Park, J.H. Park, H.S. Hwang, S.L. Choi, and J.S. Jin. 2013. Advancing the environmental administrative system for efficient environmental resources management: The roles of central and local governments (Report 2013-09-08). Sejong, Korea: Korea Environment Institute.

Kim, J.H. and T.H. Moon. 2013. A study on the effect of local delegation of monitoring and enforcement authority of pollutant discharge facilities. Korean Public Adm. Rev. 47(4):231-258.

Ko, K.H. 2016. Analysis of effect on public affairs transferred to local government. Seoul, Korea: Korea Research Institute for Local Administration.

Ko, K.Y. 2016. A study on system and performance of intergovernmental affairs devolution. Legis. Policy Stud. 8(1):57-81. Retrieved from http://www.nars.go.kr

Lee, J.H. 2000. Role sharing of environmental administration. Environmental administration toward the millennium: Policy vision and strategy. Seoul, Korea: The Korean Association for Public Administration.

Lee, S.B., J.H. Kim, Y.T. Jeong, and J.H. Jeong. 2003. A study on the strengthening of local government administrative functions. Seoul, Korea: The Korean Association for Public Administration.

Lee, S.J., M.K. Kang, C.K. Kang, J.D. Keum, I.S. Kim, H.J. Kim, S.Y. Noh, S.C. So, J.K. So, H.J. Son, S.E. Oh, D.S. Yun, K.W. Lee, J.S. Lee, S.J. Lim, S.B. Lim, J.B. Lim, W.H. Jang, E.C. Jeong, M.O. Choi, and J.L. Hong. 2008. Local government capacity and policy innovation. Seoul, Korea: Pakyoungsa.

Moon, T.H. 2013. New government's task for environmental policy and future development direction of Korean environmental policy. Korean Soc. Public Adm. 24(2):673-701. Retrieved from http://www.sapa21.or.kr

Park, S.A. 2013. Making plans for the realization of environmental welfare. Sejong, Korea: Ministry of Environment.

Park, S.A., H.S. Jeong, N.J. Jeong, W.C. Jang, J.M. Chu, C.H. Ku, and H.S. Lee. 2014. Environment and welfare. Seoul, Korea: Pakyoungsa.

Park, S.A., W.C. Jang, and H.S. Lee. 2013. Strengthening and strengthening cooperation between central government and municipalities for efficient environmental resource management. Sejong, Korea: Korea Environment Institute.

Park, S.C., Y.K. Oh, and S.K. Kim. 2015. A study on the problems and improvement plan of local offices of the Korea Ministry of Environment. Sejong, Korea: Ministry of Environment. 